\title{
Promoting Metacognitive and Linguistic Skills: Digital Learning Logs in Pre-Service Teacher Training
}

\author{
Ana Otto ${ }^{1}$, Beatriz López-Medina ${ }^{2}$ \\ ${ }^{1}$ Madrid Open University \\ ${ }^{2}$ Universidad Complutense de Madrid \\ Correspondence concerning this article should be addressed to Ana Otto, Madrid Open University, Vía de \\ Servicio A6, 15 . 28400Collado Villalba, Madrid, Spain.E-mail: anaisabel.otto@udima.es
}

\begin{abstract}
This paper reports on the implementation of digital learning logs in the context of pre-service teacher training in a distance university in Madrid. The learning log, which had been previously implemented in the subject as a learning tool, has proven to be especially useful in Covid-19 times since the students had to work more independently and could use it to reflect upon their learning without the conventional teaching they were used to. The paper has a two-fold aim: first, to analyze whether the learning logs helped in promoting students' autonomy and self-reflection, and second, to observe whether they contribute to the development of their linguistic competence in English as a foreign language. Participants of the study $(n=47)$ are students of the Primary and Infant Education degrees, specializing in English teaching, whose $\mathrm{L} 2$ level ranges between $\mathrm{B} 1$ and $\mathrm{C} 2$. At the end of half term, they were given the possibility of completing a learning log to record their learning process, review concepts and be aware of potential learning gaps and needs, and act accordingly. For this purpose, and to encourage participation, L1 or L2 could be chosen as vehicular languages. Participants were asked to complete an online questionnaire on their experience using the logs, answering questions regarding the suitability of this tool to enhance their language skills and promote effective strategies to become independent learners. The data drawn from the questionnaires submitted $(n=29)$ were later analyzed through SPSS. In addition, individual semi-structured interviews were carried out to collect information on those participants who had not completed the learning $\log (n=11)$. The findings of the study show that the vast majority of participants agree on the potential of learning logs as a useful tool to keep track of their learning process and to develop metacognitive awareness and linguistic skills.
\end{abstract}

Keywords: digital learning log, metacognition, online learning, higher education, language skills, EFL teacher training

\section{Introduction}

The role of digital learning tools which are used to facilitate the achievement of learning objectives and outcomes has been recently analyzed in the area of foreign languages for virtual and online teaching modes (Cok, 2016; Golshan \& Tafazoli, 2014; Pinto-Llorente et al., 2017, among others). Within the plethora of available instruments, learning logs have proven to be valuable instruments in face-to-face learning environments due to their versatility and potential, allowing teachers to have a better understanding of the students' learning throughout a period (Kamijo, 2013; Porto, 2007). In this respect, the interest in promoting activities to make students more independent and autonomous has led teachers to a quest for instruments that can facilitate out-of-class activities which complement in-class learning. Out-of-class activities are relevant in foreign language learning or subjects taught through an additional language since there seems to exist a correlation between the quality of out-of-class activities in the target language and the learning (Lai, Zhu \& Gong, 2015; Ohron, 2018, and Sundqvist, 2011, among others). However, scarce attention has been paid to the role of metacognition parallel to language learning through digital learning logs. This kind of activity is especially relevant in the context of distance learning since these students are required to be more autonomous and independent to compensate for the lack of face-to-face interaction with the teacher and peers (Attard, Di Lorio, Geven \& Santa, 2010; Moallem, 2015; Smith \& Darvas, 2017; Swan, Garrison \& Richardson, 2009; Traxler, Bárcena \& García-Laborda, 2015). 
This study explores pre-service teaching students' impressions on how the use of the learning logs favors metacognition and develops language skills.An online questionnaire with both Likert-scaled and open-ended questions was administered to 36 participants enrolled in the subject Advanced Didactics of English as a Foreign Language at the School of Education of a distance university in Spain who had completed this optional activity. The subject belongs to the foreign language specialization track, and students usually take the course in the third year of their undergraduate program. Students were able to monitor their learning and record any significant learning experience in their online learning logs. Upon completion of the logs, a questionnaire combining both Likert-scaled and open-ended questions was administered, and the answers were analyzed through descriptive statistics, through SPSS to observe the students' satisfaction with this tool.

For the study, two research questions were posed:

1. Do the students perceive they can enhance the metacognitive processes of autonomy, reflection, and ways to study with the use of learning logs?

2. Do the students perceive they can improve their L2 language skills with the use of learning logs?

\section{Methodology}

\section{Theoretical Background}

Students' perceptions of any learning experience provide valuable insights for teachers and students alike. For students, reflection upon their learning involves an analysis of learning outcomes which can set the basis for future learning processes. For teachers, those perceptions can be useful for future classes to be better equipped when preparing syllabus and learning activities. In the case of pre-service teachers, a cyclical review of the learning processes regarding metacognitive knowledge and metacognitive control processes is essential to be able to transfer these skills into their future professional life (Kurt, 2007), as it will help them to prepare students for the "ability to learn", the most important competence according to the Education Council (2001).

Learning tools can facilitate reflection on the learning process. A learning log, a reflective journal to monitor and reflect upon learning, is considered by Braun \& Thomas "an effective tool to help students develop cognitive awareness of their learning» (2013, p.1457). It is characterized by its wide variability, and it can present a variety of formats and structures (Friesner \& Hart, 2005). Learning logs can also vary in length, depending on the number and frequency of entries (Litzler \& Bakieva, 2017a). In addition, the activities they can gather are diverse (Litzler \& Bakieva, 2017b) and their purposes are also multifaceted. For instance, they can be used for self-assessment (Chang \& Gaery, 2005), to record learning experience (Friesner \& Hart, 2005), and as a reflection tool, which is their main use (Dewi, Warsono, \& Faridi, 2018), as reflection «opens up the opportunity for deeper learning and understanding, allowing the learner to draw conclusions» (Friesner \& Hart, 2005, p. 118).

Learning logs have proven to be successful instruments, especially in higher education (Stephens \& Winterbottom, 2010), since abstract thinking is a competence fully developed by this stage. More specifically, within the area of foreign language learning, research shows positive results on the use of helping students improve their learning autonomy (Chang \& Geary, 2015) and motivation (Litzer, 2014).

Apart from the above-mentioned benefits, there is evidence of the metacognitive awareness parallel to the cognitive development involved in the process of recording the learning experience (Braun \& Thomas, 2013). Metacognition, or the act of reflecting on how to learn, refers to the student's ability to regulate their learning processes. However, for this regulation to be effective, it is important to plan, monitor, and evaluate these learning processes that are carried out when the learning logs are used (Kurt, 2007).

Online learning logs seem appropriate for students following distance education, who are used to working with digital tools in all subjects. The use of learning logs allows the asynchronous interaction with the teacher, giving students "time to consider their thoughts, and engage with the content more deeply," (Watts, 2016, p. 27). For the teacher, digital learning logs facilitate the analysis of students' information especially regarding fastness and convenience (Friesner \& Hart, 2005), since the digital format allows for immediacy in teacher- 
student interaction, and Moodle is a user-friendly educational platform. Besides, in the case of pre-service teachers, these tools prepare them for the digital educational environments they will inevitably face in the future (Engeness, 2020; McGarr \& McDonagh, 2019; Redecker, 2017).

\section{Context}

The study was conducted within the context of a distance university in Spain. All the subjects are hosted in Moodle, a user-friendly online learning management system, which includes various formats such as lecture videos, presentations, documents, pictures, and assessments of assignments and quizzes. Teaching methodologies at this university are based on phone tutorials, video conferencing, communication in the virtual classroom, and lesson plans adapted to distance learning, audio-visual materials, databases, glossaries, Google docs, and cloud-based collaborative tools.

The dominant pedagogy underpinning teaching and learning processes at the School of Education is the promotion of critical thinking and formative assessment practice, as these two actions are commonly requested by students through the end-of-term satisfaction surveys. Assessment is, therefore, conceived in a formative way so that students are encouraged to take responsibility for their learning process at the same time that they use the English language in future educational contexts.

The Covid-19 crisis has brought to light more than ever the need of shifting towards student-centered models where teachers and students communicate and interact through the multiple tools offered by current technological platforms (Pérez-López, Vázquez-Atochero \& Cambero-Rivero, 2020; UNESCO, 2020). Although online learning is firmly established in this university, specific actions were adopted to accelerate and improve learning (World Bank, 2020) ${ }^{1}$, and to offer flexibility and enhance student autonomy (Vlachopoulos \& Makri, 2019). Among the measures implemented, we can highlight the following: more flexible deadlines, a closer follow-up of students' progress, support for online tests using the virtual platform, and extra tutorial sessions. In addition, an increase of asynchronous activities such as learning logs was adopted to cater to the exceptional circumstances derived from the Covid-19 outbreak.

\section{Participants}

47 students enrolled in Advanced Didactics of English as a Foreign Language, an elective 30-ECTS-credit subject in the Degree of Education, were invited to complete the above-mentioned questionnaire on learning logs. Out of the 47 participants, 36 handed in the learning logs, and 29 from this group filled in the questionnaire. Semistructured interviews were held with those who had not handed in the learning logs to collect information on the subject matter.

Regarding the demographics, $82.8 \%$ of students are over 25 years old, and there is a high prevalence of women (86.2\%). Most of them already hold a degree and combine studies with work-life, an aspect which makes it difficult to attend online synchronous lessons. Students, whose L2 level ranges between B1 and C1, had previously pursued basic didactics of foreign language teaching so they were supposed to have an awareness of the underlying theoretical principles of teaching EFL.

\section{Instruments}

A total of two tools were deployed to gather the data consisting of a questionnaire and semi-structured interviews. The questionnaire administered to students (Appendix) was adapted from Litzler \& Bakieva's (2017a). It involved six closed questions in the form of a Likert-scale, and four open-ended questions since both kinds allow analyzing data from a qualitative and quantitative perspective (Dörnyei \& Taguchi, 2009). The first closed question, on general satisfaction about the learning log, ranged from one to ten to explore responses in greater depth. Questions two to six, referring to specific features of the log, ranged from one to seven.

The questions referred to the learning log which weighed $10 \%$ of the student's final grade followed Jarvis' model of reflection (2001), which categorizes four levels of reflective learning conveying a progression towards

\footnotetext{
1 The World Bank. (2020). Lessons for Education during the Covid-19 Crisis. https://inyurl.com/hlgx925n
} 
critical or higher-order thinking: descriptive (non-reflective), descriptive reflection, dialogic reflection, and critical reflection.

The first section in the activity ("Things I learned") can be subsumed into the category of descriptive reflection, where the student is invited to comment on the main topics in each unit. The second section ("Something I found interesting") went a bit further in metacognition and thus, it can be considered critical reflection, as it offered students the opportunity to examine the topics in-depth, develop opinions and make value decisions. Lastly, in the last section ("Some questions you still have") students were also introduced to critical thinking as they assessed their knowledge by posing questions to the teacher. Instructions for the learning log were as follows:

\section{Your learning log}

This activity deals with the process of reflecting on your work. You need to

write a separate entry and reflection for each unit using the template below reflecting on the following:

- $\quad$ Things I learned

- $\quad$ Something I found interesting

- Some questions you still have

Bear in mind that the entries can be written in Spanish or English.

Remember the deadline!

After the students had completed the online learning logs, the questionnaire was written in Spanish, and administered through an online Google form. Likewise, to elicit feedback on the typical reasons for not handing in the logs, individual semi-structured interviews were conducted over the phone. Finally, data from the Likertscale questions were entered into SPSS for statistical analysis, and for the open-ended questions, responses were analyzed to gather additional information on students' views.

In addition, semi-structured interviews were conducted in Spanish to collect insights from participants who have not used the log as a learning tool through the term. It is believed that this type of interview allows informants to express their views in their terms, and can provide reliable qualitative data.

\section{Procedure}

Over the course, students were invited to complete the digital learning logs choosing between English and Spanish, since the main purpose of this activity was to promote reflection over the use of language (Hattie \& Timperley, 2007). Feedback on language use (grammar accuracy, vocabulary use, and word order, among other aspects) was provided to those students who chose English, the vehicular language for the final exam. However, to favor metacognitive processes and to allow students to express themselves freely, no penalization was made on mistakes if they did not impede comprehension (Bigelow \& Ranney, 2005).

Apart from the individual comments accompanying the grade, feedback was also provided by the teacher through videos where questions regarding the content of the subject along with linguistic issues were addressed. The answers to these questions posed by students were then grouped by the teacher around common topics. Besides, the teacher also recommended additional resources and readings on topics of general interest. These videos were publicly available in the virtual classroom so that all students could benefit from their peers' contributions and, thus, learn from each other.

\section{Results}

Overall, the descriptive data from the closed questions indicate that the participants in this study are satisfied with the use of learning logs in the subject. To Q0 related to the general impression of the logs: Upon completion of the learning log, indicate your level of satisfaction from 1 (very unsatisfied) to 10 (very satisfied), $65.5 \%$ of the students give it a score of 9 or 10, the rest of participants $34.4 \%$, between 7 and 8 . These results offer the highest mean score (mean $=8.76, \mathrm{Std}_{.}=.912$ ), therefore showing the learning log as a valuable learning tool according to the students' opinion. This general satisfaction can also be noticed in the students' comments to 
open-ended questions where they indicate this is an interesting tool suitable for primary education contexts, considering its potential use in their future teaching profession:

It's a very useful tool. Many times, we teachers act in the classroom without noticing what we do, in a
mechanical way. We need to reflect critically about our teaching style; sometimes, we apply rules
from manuals we have read but we never take notes- this leads us to forget important information
either because we are in a constant rush or because we are not used to doing that. Keeping a diary or
journal is good as it can help us as a guide we can rely on according to our needs in the class (St02).

I'd love to use this in my future teaching practice, as I have checked it can help you reflect on what you have learned (St07).

Finally, those students who had not completed the learning logs explained it is a useful tool they would all have completed $(n=11)$ had it not been for the lack of time derived from the difficulties to carry out studies, work, or family issues throughout and after lockdown. As one of the students pointed out, one of the reasons was the difficulty of carrying out the observed teaching practice which is mandatory in the Education degrees and other academic tasks because of the past and current situation:

As for me, I couldn't do this activity. I was called up to start my observed teaching practice. I couldn't do it last academic year; everything became so complicated and I am still trying to balance this practice, studying the subjects, kids, and everything. To this day, I am still 'huffing and puffing' with the syllabus. I am trying to catch up and I will certainly complete the next one, in which I intend to include this reflection too, if possible. [...]This is an interesting activity and it can help us to be more open-minded, and reflect on our educational work (St01).

\section{Research Question 1: Do the Students Perceive They Can Enhance the Metacognitive Processes of Autonomy, Reflection, and Ways to Study with the Use of Learning Logs?}

The descriptive data regarding autonomy (Q1), ways to study (Q3), and reflection (Q4), indicate a mean higher than 5.00 (out of 7.00 in a 1 to 7 Likert scale) showing, therefore, the participants' positive views on these features. To the statement Q1 The learning log has helped me to increase my autonomy when studying the subject, over three quarters (75.8\%) rank this item between six and seven; With a mean of 5.76 and an Std. of 1.272, these questions offer a similar mean to Q3: The learning log has helped me to explore and find other ways to study, (mean= 5.38). The answers in the latter case are split with slightly over a half (51.7\%) rank it between 6 and 7 (Std. =1.545). It is interesting to observe, nevertheless, how in Q4, The learning log has assisted me to study the subject in-depth and clarify doubts, also related to metacognition, a vast majority of participants (86.2\%) rank this question between 6 and 7 (mean= 6.28 and Std. $=.882$ ).

\section{Research Question 2: Do the Students Perceive They Can Improve Their L2 Language Skills with the Use of Learning Logs?}

English was the preferred language for nearly two-thirds of the students (62.1\%). Since they pursue a major in English, most of them want to use the language as much as they can: English is essential for my future profession as a teacher, so I decided to write the learning log in English to practice (St16). Those who opted for writing the log in Spanish (37.9\%), report not feeling comfortable with using English and they seem to be afraid of making mistakes or not being clear enough. As one of the participants points out: I don't have the required level, I'm afraid. Spanish is my mother tongue and thus, it is more natural to me to write in this language. I am proficient in Spanish so I can express myself better. Also, as I don't have much time to complete the tasks, I can finish them quicker (St03).

For Q2, The learning log has helped me to improve my English level, roughly two thirds (65.5\%) of students who wrote the logs in English state that they managed to practice and improve their L2 level with the help of the teachers' corrections and comments (answers ranked between six and seven in the 1 to 7 Likert scale). Only $6,85 \%$ of students consider they did not improve significantly, maybe because their level was good enough $($ mean $=5.76$, Std. $=1.576)$. 
The successful acceptance of this tool might be due to the explanatory videos recorded by the teacher providing answers to all the students' questions regardless of the language they used for that purpose. The wide majority of respondents (96.5\%) recognize the value of videos as educational resources in asynchronous online contexts during the pandemic. The mean of 6.62 out of 7 and the lowest Std. in the questionnaire (Std. $=.561$ ) demonstrate the students' evident support to the videos as a useful resource complementing the learning log.

\section{Table 1}

Questionnaire Descriptive Statistics

\begin{tabular}{lccccc}
\hline & $\boldsymbol{N}$ & Minimum & Maximum & Mean & Std. Deviation \\
\hline Satisfaction & 29 & 7,00 & 10,00 & 8,76 &, 912 \\
Autonomy & 29 & 1,00 & 7,00 & 5,76 & 1,272 \\
English Language & 29 & 1,00 & 7,00 & 5,76 & 1,573 \\
Ways to study & 29 & 1,00 & 7,00 & 5,38 & 1,545 \\
Reflection & 29 & 4,00 & 7,00 & 6,28 &, 882 \\
Videos & 29 & 5,00 & 7,00 & 6,62 &, 561 \\
Valid N (listwise) & 29 & & & & \\
\hline
\end{tabular}

\section{Discussion}

The case study presented here has described and evaluated the use of learning logs as a reflective practice in an undergraduate course at an online university during the pandemic. The study shows the students value the learning logs to improve the planning, organization, and evaluation of their work, making use not only of metacognitive but also cognitive strategies (Oxford, 2016). These skills become even more relevant during difficult times such as a pandemic, where the students need to draw on more self-regulation and motivation. Also, the critical reflection promoted by the learning logs can compensate for the absence of face-to-face class interaction and implement a student-centered approach. In this respect, and as previous studies have demonstrated (Chang \& Lin, 2014; Cheng, 2017), in online learning, students using the learning logs benefit from a more relaxed atmosphere, have time to think on their own, and they are not constrained from the presence of the teacher and peers when posing questions.

Likewise, in this context, students can take advantage of wait-time, an essential feature in EFL, which gives way to more student contributions (Alsaadi \& Atar, 2019). Overall, participants seem to be satisfied after using the logs, which contributed to their learning through reflective practice. As can be seen from their entries and the numerous questions posed to the teacher, topics were examined in-depth, and students had the opportunity to develop their opinions regardless of the language they used. Likewise, the logs helped them share their knowledge and opinions on interesting subjects, such as contexts for learning English, teachers' beliefs, and ways of developing positive attitudes towards English. For instance, concerning the topic of classroom management, some participants are eager to know the best ways to motivate students in heterogeneous groups with different English levels and ambitions, and how to create a warm atmosphere with disruptive children. Regarding the use of English, to quote a further example, some teachers are concerned that their level of English might be insufficient to teach upper levels: Can my worries with English affect my teaching? I have a positive attitude to English, however, sometimes I can be less confident about my own English because not all the topics are equally difficult, but I always try to do my best. Although I can have doubts, I look for a solution or I ask for help. My deeper concern is: Will my level affect my pupils? Will I be teaching them correctly? (St14).

As for language achievement, some students still find reflective writing challenging in English, maybe because their English level in this specialization track is ranked between B1 and C1. Although they are supposed to improve their language skills throughout the course and degree, and as English is the language they will use in their professional lives, it is important to notice that some of them are still reluctant to use it, as they do not feel confident when writing or talking, probably due to their age. This is corroborated by the fact that only two students out of the whole group agreed to share their written work with their peers in the virtual class and 
following Li, Ogata, Hou, Uosaqui \& Mouri (2013), whose study reflects the participants' difficulties when learning from their peers' logs. The authors, however, consider that "a learner's learning log cannot merely be available for himself, but can also be shared with other learners who have the same learning needs" (p. 363).

Despite participants' reluctance to share their work, the videos recorded by the teacher and uploaded to the virtual platform allowed the implementation of oracy and discussion in the online learning environment, which often lacks wider means of synchronous interaction among students. In fact, by sharing questions about the main topics on English didactics, the group helped to create an 'open classroom climate', and build a virtual learning community based on self-reflection and communication among peers, thus empowering the students as the protagonists of their learning process. This commitment towards their learning is also depicted in the students' comments about the future use of this tool, in line with Stephens and Winterbottom's findings (2010), since participants indicate they can transfer skills to their future teaching profession and state that they have gained confidence in their abilities.

About their future career, they advocate for the following suggestions to be implemented shortly: Learning logs can be designed around practical case studies.It would be nice to relate the logs with the most common situations we can find as teachers of English: describe teaching-learning situations in relation to the syllabus to provide an answer for the existing problems (St15). As for the language choice in writing the logs, some of those who chose English believe they made a big effort which should be somehow compensated as can be seen from some of their comments: To encourage all students to write in English. To give a higher score to those who write in English (St08).

Finally, they also propose to share the main conclusions from each participant so that all learners can learn from each other. Furthermore, the fact that they can freely complete the learning logs and also receive feedback through the videos supports the double function of technology as a resource chosen by the teacher to compile information on the learning and as a dialogic interface with the class, in line with García-Esteban \& GarcíaLaborda (2016).

\section{Conclusion}

According to the results of the study, and as was pointed out in the discussion, students appeared to be highly motivated to use learning logs in this subject, as they seem to promote self-learning and critical thinking, and prepare them for future life regarding both language and academic skills. It is important to notice that the critical reflection promoted by the learning logs can compensate for the absence of face-to-face class interaction and implement a student-centered approach, which, in turn, allows students to work at their own pace while maintaining interaction with their peers.

Considering the students' comments, what follows is a series of recommendations for practitioners on the use of learning logs in online contexts: First, in the future, high proficient students should be encouraged to complete their logs in English. This would assist them in the writing of academic English, a condition which they will inevitably have to follow in the final written exam. As for those with low English levels, students can be offered the option to write the logs using their mother tongue rather than losing critical reflection at the cost of language proficiency.

Second, to conduct the assessment in a formative way, a rubric to measure students' achievement in this task to avoid subjectivity in the assessment process deems necessary. This rubric would help students to be informed and familiarized with the assessment criteria, and the teacher to correct the activity following a criterionbased assessment rather than a norm-based one.

Furthermore, although students taking part in this study took advantage of the teacher's videos, learning logs, as some of the students suggest, could be publicly shared in the virtual class ensuring confidentiality so that all students can see their peers' work and learn from each other. Sharing students' work can contribute to higher quality work as they can check their assignments before they are published, see what other students do, find their flaws, critically evaluate other students, and finally, create an online learning community where participants integrate feedback effectively and improve future work. 
Finally, research on the topic of digital learning resources (still scarce) should be conducted to analyze the impact on pre-service teachers' FL learning and reflection on content matter. After the implementation of the learning logs, the positive impact on the students' learning has exceeded all expectations, making researchers wonder about their implementation in face-to-face contexts to compare learning outcomes and results. In this respect, a larger sample would be needed to obtain a more accurate picture of the students' perceptions. We should, therefore, explore the possibilities offered by the digital learning logs, exploiting their potential for reflecting on the learning processes in subjects taught through an additional language.

\section{Declaration of Competing Interest}

None declared.

\section{References}

Alsaadi, N. S. M., \& Atar, C. (2019). Wait-time in material and classroom context modes. International Journal of Contemporary Educational Research, 6(1), 53-69. https://doi.org/10.33200/ijcer.542495

Attard, A., Di Lorio, E., Geven, K., \& Santa, R. (2010). Student-Centred Learning - Toolkit for students, staff and higher education institutions. European Students Union.

Bigelow, M., \& Ranney, S. (2005). Pre-service ESL teachers' knowledge about language and its transfer to lesson planning. In N. Bartels (Ed.), Applied Linguistics and language teacher education (vol. 4, pp. 179-200). Springer Science.

Braun, S., \& Thomas, S. (2013). Student perceptions of the use of learning logs to teach public relations writing. Procedia - Social and Behavioral Sciences, 93, 1456 - 1460. https://doi.org/10.1016/j.sbspro.2013.10.063

Chang, L. Y., \& Geary, M. P. (2015). Promoting the autonomy of Taiwanese EFL learners in Higher Education by using self-assessment learning logs. Studies in English Language Teaching, 3(4), 339-354. https://doi. org/10.22158/selt.v3n4p339

Chang, M., \& Lin, M. (2014) The effect of reflective learning e-journals on reading comprehension and communication in language learning. Computers and Education, 71, 124-132. https://doi.org/10.1016/j. compedu.2013.09.023

Cheng, G. (2017). The impact of online automated feedback on students' reflective journal writing in an EFL course. The Internet and Higher Education, 34, 18-27. https://doi.org/10.1016/j.iheduc.2017.04.002

Cok, T. (2016). ICT-supported language learning tools for Chinese as a foreign language: A content review. Revija Za Elementarno Izobrazevanje, 9(3), 103-120.

Council of Europe. (2001). Common European Framework of Reference for languages: Learning, teaching, assessment. Cambridge University Press.

Dewi, N. M., Warsono, W., \& Faridi, A. (2018). Integrating collaborative strategic reading with learning logs: An alternative method to develop reading comprehension. English Education Journal, 8(2), 169-177. https://doi. org/10.15294/eej.v8i3.21406

Education Council. (2001). The concrete future objectives of education and training systems (Brussels, 14 February, 2001). European Council.

Engeness, I. (2020). Developing teachers' digital identity: Towards the pedagogic design principles of digital environments to enhance students' learning in the $21^{\text {st }}$ century. European Journal of Teacher Education, 43(5), 1-19. https://doi.org/10.1080/02619768.2020.1849129

Dörnyei, Z., \& Taguchi, T. (2009). Questionnaires in second language research: Construction, administration, and processing. Routledge.

Friesner, T., \& Hart, M.(2005). Learning logs:Assessment or research method. The Electronic Journal of Business Research Methodology, 3(2), 117-122.

García Esteban, S., \& García Laborda, J. (2016). Human communicative dialogic practices in content and language-based educational interactions with technology. The Anthropologist, 25(3), 220-228. https://doi.or $\mathrm{g} / 10.1080 / 09720073.2016 .11892110$

Golshan, N., \& Tafazoli, D. (2014). Technology-enhanced language learning tools in Iranian EFL context: Frequencies, attitudes and challenges. Procedia - Social and Behavioral Sciences, 136, 114-118. https://doi. org/10.1016/j.sbspro.2014.05.299

Hattie, J., \& Timperley, H. (2007). The power of feedback. Review of Educational Research, 77(1), 81-112. https:// 
doi.org/10.3102/003465430298487

Jarvis, P. (2001). Journal writing in Higher Education. New Directions for Adult \& Continuing Education, 90, 70-86. https://doi.org/10.1002/ace.23

Kamijo, T. (2013). Applying student learning logs for evaluating reading strategies in a sophomore EAP course: Extended research and its implications. Ritsumeikan University International Language and Culture Research Institute Bulletin, 24(4), 183-197.

Kurt, M. (2007, May 7). Activating metacognition through Online Learning Log (OLL) [Conference presentation]. International Educational Technology Conference. https://www.learntechlib.org/p/62187/

Lai, C., Zhu, W., \& Gong, G. (2015). Understanding the quality of out-of-class English learning. TESOL Quarterly, 49(2), 278-308. http://www.jstor.org/stable/43893754

Li, M., Ogata, H., Hou, B., Uosaki, N., \& Mouri, K. (2013). Context-aware and personalization method in ubiquitous learning log system. Educational Technology \& Society, 16(3), 362-373.

Litzler, M.F., (2014). Independent study logs: Guiding and encouraging students in the process of language learning. Journal of Language Teaching and Research, 5(5), 994-998.

Litzler, M. F., \& Bakieva, M. (2017a). Learning logs in foreign language study: student views on their usefulness for learner autonomy, Didáctica. Lengua y Literatura, 29, 65-80. http://dx.doi.org/10.5209/DIDA.57130

Litzler, M.F., \& Bakieva, M. (2017b). Students' out-of-class activities for practicing English as a foreign language: A log study. International Journal of Scientific Study, 5(8), 10-19. https://doi.org/10.17354/ijssNov/2017/2

McGarr, O., \& Mcdonagh, A. (2019). Digital competence in teacher education. Output 1 of the Erasmus+ funded Developing Student Teachers' Digital Competence (DICTE) project. https://dicte.oslomet.no/

Moallem, M. (2015). The impact of synchronous and asynchronous communication tools on learner selfregulation, social presence, immediacy, intimacy, and satisfaction in collaborative online learning. The Online Journal of Distance Education and e-learning, 3(3), 55-77. https://bit.ly/3aK571c

Orhon, Y. (2018). An investigation of out-of-class language activities of tertiary level. EFL Learners Education Reform Journal, 3(1), 1-14. https://doi.org/10.22596/erj2018.0301.1.14

Oxford, R. (2016). Teaching and researching language learning strategies: Self-regulation in context. Routledge.

Pérez-López, E., Vázquez Atochero, A., \& Cambero Rivero, S. (2020). Educación a distancia en tiempos de Covid-19: Análisis desde la perspectiva de los estudiantes universitarios [Online education in Covid times: An analysis of university students' perspectives]. RIED. Revista Iberoamericana de Educación a Distancia, 24(1), 331-350. http://dx.doi.org/10.5944/ried.24.1.27855

Pinto-Llorente, A. P., Sánchez-Gómez, M. C., García-Peñalvo, F., Casillas-Martín, S. (2017). Students' perceptions and attitudes towards asynchronous technological tools in blended-learning training to improve grammatical competence in English as a second language. Computers in Human Behavior, 72, 632-643. https://doi. org/10.1016/j.chb.2016.05.071

Porto, M. (2007). Learning diaries in the English as a foreign language classroom: a tool for accessing learners' perceptions of lessons and developing learner autonomy and reflection. Foreign Language Annals, 40(4), 672-696. https://doi.org/10.1111/j.1944-9720.2007.tb02887.x

Redecker, C. (2017). European framework for the digital competence of educators. Publications Office of the European Union. https://doi.org/10.2760/159770

Smith, V. D., \& Darvas, J. W. (2017). Encouraging student autonomy through higher order thinking skills. Journal of Instructional Research, 6, 29-34.

Stephens, K., \& Winterbottom, M. (2010). Using a learning log to support students' learning in biology lessons. Journal of Biological Education, 44(2), 72-80. https://doi.org/10.1080/00219266.2010.9656197

Sundqvist, P. (2011). A possible path to progress: Out-of-school English language learners in Sweden. In P. Benson, \& H. Reinders (Eds.), Beyond the language classroom (pp. 106-118). Palgrave Macmillan.

Swan, K., Garrison, D. R., \& Richardson, J. (2009). A constructivist approach to online learning: The community of inquiry framework. In C. R. Payne (Ed.), Information technology and constructivism in higher education: Progressive learning frameworks (pp. 43-57). IGI Global.

Traxler, J., Barcena, E., \& García-Laborda, J. (2015). Mobile technology for foreign language teaching: Building bridges between non-formal and formal scenarios. Journal of Universal Computer Science, 21(10), 1234-1247.

UNESCO. (2020). Covid-19 and higher education: Impact and recommendations. https://bit.ly/2ZyhQyW

Vlachopoulos, D., \& Makri, A. (2019). Online communication and interaction in distance higher education: A framework study of good practice. International Review of Education, 65, 605-632. https://doi.org/10.1007/ s11159-019-09792-3

Watts, L. (2016). Synchronous and asynchronous communication in distance learning: A review of the literature. Quarterly Review of Distance Education, 17(1), 23-32. 


\section{APPENDIX}

\section{LEARNING LOG QUESTIONNAIRE}

Learning logs in Advanced Didactic of English as a Foreign Language.

The following questionnaire aims to gather information about the learning logs you have completed in your learning activity 1 (LA1). This information will help your teacher to improve the activity in the future. Responses are confidential and will be treated anonymously. Thank you very much for your collaboration!Dr. Ana Otto

*Compulsory

\section{DEMOGRAPHICS}

1. What is your gender?* $\square$ Female $\square$ Male $\square$ Prefer not to answer $\square$ Other:

2. What is your age?* $\square 19-21 \quad \square 22-24 \quad \square$ Over 25

\section{THE LEARNING LOG}

3. I wrote the learning log in $* \square$ English $\square$ Spanish

4. Why did you choose that language?*

5. On a scale from one to then, how satisfied are you after having completed the learning log? (1: wholly satisfied/10: highly satisfied) *

$$
\begin{array}{llllllllll}
1 & 2 & 3 & 4 & 5 & 6 & 7 & 8 & 9 & 10
\end{array}
$$

\section{PLEASE INDICATE TO WHAT EXTENT YOU AGREE WITH THE STATEMENTS BELOW}

6 The learning log has helped me to learn autonomously *

$$
\begin{array}{llllllllll}
1 & 2 & 3 & 4 & 5 & 6 & 7 & 8 & 9 & 10
\end{array}
$$

7 The learning log has helped me to improve my English level *

$$
\begin{array}{lllllllllll}
1 & 2 & 3 & 4 & 5 & 6 & 7 & 8 & 9 & 10
\end{array}
$$

8 The learning $\log$ has helped to find alternative ways to study *

$$
\begin{array}{llllllllll}
1 & 2 & 3 & 4 & 5 & 6 & 7 & 8 & 9 & 10
\end{array}
$$

9 The learning log has helped me to reflect about the topics and better understand the subject *

$$
\begin{array}{llllllllll}
1 & 2 & 3 & 4 & 5 & 6 & 7 & 8 & 9 & 10
\end{array}
$$

10 The videos in which the teacher answers the questions posed in the learning log have helped me to study and clarify doubts *

$$
\begin{array}{llllllllll}
1 & 2 & 3 & 4 & 5 & 6 & 7 & 8 & 9 & 10
\end{array}
$$

\section{ANSWER THE FOLLOWING QUESTIONS BY JUSTIFYING YOUR ANSWER}

11 Do you think you will use the learning log as a teaching/learning tool in your future teaching profession? Why (not)? *

12 Would you suggest anything to improve the learning log so that it promotes and enhances student autonomy? *

13 If you wish to comment on the learning log or the videos associated with this activity, please use the space below: *

Thank you for your collaboration. 